\title{
A contribuição das equipes multiprofissionais para a visibilidade da Política Nacional de Saúde da Pessoa Idosa para os idosos
}

\author{
Patrícia Barreto Cavalcanti*, Priscila de Almeida da Costa**, \\ Ana Paula Rocha de Sales Miranda***, Alecsonia Pereira Araújo****
}

\section{Resumo}

O envelhecimento populacional é um fenômeno que está ocorrendo de forma rápida e intensa na população brasileira. Para esse cenário, foram estabelecidas leis, portarias e decretos para atender principalmente às necessidades de saúde da população idosa, dentre esses instrumentos legais está a Política Nacional de Saúde da Pessoa Idosa. Assim, esta pesquisa tem como objetivo verificar se a atuação da equipe multiprofissional de saúde contribui para o conhecimento e a implementação dessa política em meio a usuários assistidos por uma instituição de longa permanência localizada em João Pessoa, PB. O artigo procura traçar o perfil dos idosos assistidos e captar a percepção deles acerca das ações desempenhadas pela equipe multiprofissional e investigar como ocorre a abordagem dos profissionais e o modelo de atenção à saúde. Para a coleta dos dados, utilizou-se a entrevista semiestruturada e a observação com registro em diário de campo. Trata-se de um estudo observacional, de campo, do tipo descritivo, com abordagem quantitativa e qualitativa, realizado com uma amostra de 29 pessoas selecionadas por conveniência, especificamente oito profissionais da equipe multiprofissional e 21 idosos. Os resultados indicaram a feminização da velhice. Ademais, constatou-se que diante das múltiplas necessidades dos idosos apresentadas ainda é preciso avançar na implantação e visibilização de políticas sociais voltadas para a integralidade do cuidado, tendo em vista que metade da amostra profissional consultada conhece tangencialmente o aparato legal que protege o idoso, o que explica sobremaneira a falta de orientação profissional fornecida em relação aos direitos sociais atestada por $52,4 \%$ dos idosos entrevistados.

Palavras-chave: Equipe multiprofissional. Idoso. Política Nacional de Saúde da Pessoa Idosa.

* Doutora em Serviço Social e Política Social. Professora associada IV do Departamento de Serviço Social da Universidade Federal da Paraíba. Pesquisadora do CNPq. Coordenadora do Setor de Estudos e Pesquisas em Saúde e Serviço Social. Endereço para correspondência: Universidade Federal da Paraíba. Centro de Ciências Humanas Letras e Artes, Bloco IV - Cidade Universitária, João Pessoa. PB, Brasil. CEP 58.051970. E-mail: patriciabcaval@gmail.com

** Mestranda em Serviço Social pela Universidade Federal da Paraíba. Especialista em Gestão Pública. E-mail: priscilacosta17@hotmail.com

*** Doutora em Serviço Social pela Pontifícia Universidade Católica de São Paulo. Professora adjunta I do Departamento de Serviço Social da Universidade Federal da Paraíba. Pesquisadora do Setor de Estudos e Pesquisas em Saúde e Serviço Social. E-mail: aprmiranda2@gmail.com

**** Mestre em Serviço Social pela Universidade Federal da Paraíba. Professora assistente II do Departamento de Serviço Social da Universidade Federal da Paraíba. Pesquisadora do Setor de Estudos e Pesquisas em Saúde e Serviço Social E-mail: alecsonia@hotmail.com

$\rightarrow$ http://dx.doi.org/10.5335/rbceh.v13i2.5415

Recebido em: 25/09/2015. Aceito em: 17/08/2016. 


\section{Introdução}

O envelhecimento populacional é um fenômeno de amplitude mundial e o Brasil também está inserido nesse cenário. Trazer para a análise a temática da pessoa idosa no contexto da sociedade atual sob a ótica dos direitos que estão estabelecidos na legislação brasileira é imprescindível para estudar-se o envelhecimento humano. Nesse contexto, é importante destacar os instrumentos legais que amparam os direitos dos idosos, que foram conquistados a partir das lutas dos trabalhadores por direitos sociais que ocorreram entre as décadas 1960 e 1980. Dentre os direitos assegurados, a saúde passa a ser preconizada como um direito fundamental, assegurada nas seguintes legislações: Constituição federal de 1988, Lei no 8.842/1994 Política Nacional do Idoso (PNI) -, Lei no 10.741/2003 - Estatuto do Idoso -, Resolução no 145/2004 - Política Nacional de Assistência Social -, Portaria no 2.528/2006 - Política Nacional de Saúde da Pessoa Idosa (PNSPI). Tal aparato legal constitui um marco para afirmar a priorização desse segmento populacional na construção de políticas públicas.

Contudo, importa salientar que a Política Nacional do Idoso guarda inúmeras peculiaridades já que é atravessada fundamentalmente pelas políticas setoriais que encerram a seguridade social brasileira: saúde, previdência e assistência social. Portanto, analisar a PNI pressupõe refletir se não acerca dos avanços, a respeito dos recuos que tais políticas vêm sofrendo. Pressupõe ainda observar sua organização, estabelecida em níveis de complexidade de atenção equivalentes aos níveis de complexidade das políticas de saúde e assistência (básica, média e alta). Por fim, considerar que tais políticas sociais necessitam urgentemente se pautarem pelo princípio da equidade em relação à atenção diposta ao segmento idoso.

Ancoradas no avanço de garantias de direitos estabelecidos na constituinte de 1988, as políticas que compõem a seguridade social, notadamente a saúde, experimentaram inovações em termos de gestão com a estratégia da descentralização, organização dos serviços e participação da sociedade civil com a criação dos fóruns de controle social.

No que se refere à assistência social, a inclusão da perspectiva da seguridade social como parâmetro para se pensar a proteção social também resultou em avanços consideráveis, tendo como resultado, anos mais tarde, a construção da perspectiva de política pública com a criação do Sistema Único de Assistência Social. Contudo, tais avanços não foram acompanhados de financiamento compatível, o que evidenciou na década de 1990 a fragilidade do escopo em que as garantias obtidas em 1988 apresentavam e a mudança de rota adotada pelos últimos governos, de focalizar e selecionar suas respostas aos mais vulnerabilizados. No âmbito da Previdência Social brasileira, as reformas operadas no lastro da reforma gerencial do Estado na década de 1990 também, por conseguinte, causaram impactos negativos na gestão da PNI (SPOSATI, 2009). 
A PNI detém, em seu arcabouço, um conjunto de ações governamentais que prevê um suporte para que sejam assegurados os direitos sociais no decurso do envelhecimento, considerando que "o idoso é um sujeito de direitos e deve ser atendido de maneira diferenciada em cada uma das suas necessidades: físicas, sociais, econômicas e políticas" (CAMARANO, 2004, p. 269). Assim, a PNI transversal tais políticas e sofre, indubitavelmente, seus reflexos, justamente por essa interdependência na prestação dos serviços. Essa relação sistêmica se expressa logicamente pela questão estrutural que circunda a proteção social brasileira em sua totalidade, mas, no caso específico do segmento idoso, outros fatores devem ser considerados. A esse respeito Amazoneida afirma que:

Torna-se, portanto, urgente pensar num perfil de políticas sociais que, a despeito das limitações impostas pelo modelo socioeconômico dominante, se baseie nas análises (Juaréz, 1998): Das condições de vida dos idosos, detectando mudanças nos planos pessoal e social; Das situações específicas de pobreza, mal-estar e marginalização a que muitos idosos estão submetidos; Dos fatores políticos, sociais, econômicos e culturais que influenciam as condições de vida dos idosos, com vista à revisão das políticas sociais vigentes e à proposição de outras novas; Das convergências e divergências dos esquemas de políticas sociais nacionais com os de outros países para, por meio da comparação e do contraste, retirar lições positivas (2005, p. 8).

A esse pensamento de Amazoneida (2005), acrescenta-se que tal perfil pretenso de políticas de corte social (como a saúde) deve considerar o pluralismo moral inerente à contemporaneidade, $o$ qual expressa o impasse entre a justiça entendida como igualdade de acesso indiscriminado para toda a sociedade civil, que defende a saúde como um direito universal, e a justiça como equidade, que indica que em casos de disputa se deve lançar mão da assertiva de tratar de modo desigual os desiguais. Essa necessidade surge como vital em se tratando das ações de saúde voltadas para os idosos, já que a velhice incorpora um vasto leque de demandas (no escopo da previdência, assistência social e habitação), sendo a mais frequente a demanda em saúde, notadamente vinculada ao tratamento, à reabilitação e à cura de patologias crônicas próprias do processo de envelhecimento.

A esse respeito, autores como Veras (2009), Minayo, Hartz e Buss (2000), Camarano e El Ghaouri (1999) provocam o debate acerca dessa problemática, assinalando o despreparo da sociedade brasileira, sobretudo, a falta de aparato estatal via políticas públicas no enfrentamento dessa questão. Particularmente, tais autores sinalizam a defasagem entre os serviços públicos de saúde e a realidade epidemiológica que o segmento idoso sugere atualmente e que tende a se ampliar.

Ademais, pesquisas realizadas pelo Instituto Brasileiro de Geografia e Estatística (2011) indicaram que, em 2000, um em cada dez brasileiros tinha mais de 60 anos, prevendo-se que se deverá alcançar 1:5 até 2050 . No censo realizado em 2010 , o número de pessoas idosas era de 20.622.018, enquanto que em 2000, o número era de 14.536.029, versus 10.722.705 em 1991. 
A magnitude da transição demográfica; do complexo perfil epidemiológico; da escassez de profissionais qualificados e ambientes devidamente planejados; do desemprego estrutural; do empobrecimento dos (as) trabalhadores (as); da flexibilização dos direitos sociais conquistados; do desmantelamento dos equipamentos, inclusive os da saúde pública, para atender à referida população; [...] que compõem e extrapolam a formalizada tríade da Seguridade Social [no Brasil] fazem parte do cenário (PAIVA, 2014, p. 168).

Diante dessa realidade, o cuidado realizado ao sujeito em processo de envelhecimento envolve o próprio idoso, sua família, o cuidador e a comunidade na qual ele vive. No caso das instituições de longa permanência para idosos (Ilpis), esse cuidado passa a ser desenvolvido, também, pela equipe multiprofissional de saúde. Dessa maneira, é fundamental que tais equipes estejam preparadas para atender, de forma integral e equânime, às necessidades do idoso.

[...] uma equipe multiprofissional é definida por uma modalidade coletiva de trabalho que se configura na relação recíproca entre as múltiplas intervenções técnicas e a interação dos agentes de diferentes áreas profissionais, criando um campo de aproximação de saberes concentrados em busca de soluções para os problemas de saúde (SILVA et al., 2013, p. 154).

Assim, com base na perspectiva citada, o Setor de Estudos e Pesquisas em Saúde e Serviço Social da Universidade Federal da Paraíba desenvolve estudos que dão destaque à realidade das Ilpis bem como à complexidade que envolve o trabalho multiprofissional na produção do cuidado em saúde voltado ao envelhecimento institucionalizado. O artigo em questão é fruto de tais estudos e reflete os resultados de uma pesquisa desenvolvida na instituição de longa permanência para idosos Vila Vicentina Júlia Freire, entidade filantrópica, localizada em João Pessoa, PB. A instituição é vinculada à Sociedade São Vicente de Paulo e foi fundada em 23 de abril de 1944. Ressalta-se que, no momento da coleta de dados, a instituição abrigava 66 idosos de ambos os sexos.

Nessa perspectiva, o objetivo principal deste estudo foi analisar se a atuação da equipe multiprofissional de saúde da Vila Vicentina Júlia Freire contribui para o conhecimento e a implementação das diretrizes da PNSPI no caso de usuários que residem nessa instituição. A proposta teve como questões específicas: a) identificar o acesso e o conhecimento da equipe multiprofissional sobre os direitos assegurados na Política Nacional de Saúde da Pessoa Idosa; b) averiguar a percepção dos idosos quanto à atuação da equipe multiprofissional na Vila Vicentina Júlia Freire; c) investigar como ocorre a abordagem dos profissionais e o modelo de atenção à saúde, avaliando se focaliza $o$ aspecto preventivo ou o curativo.

\section{Materiais e método}

Trata-se de um estudo observacional, de campo e descritivo com uma amostra de profissionais de saúde que atuam na Vila Vicentina Júlia Freire e dos idosos residentes na instituição. $\mathrm{Na}$ pesquisa, foi utilizada a abordagem qualitativa-quantitativa que teve o intuito de des- 
crever as características que permeiam a realidade da equipe multiprofissional de saúde e dos idosos.

Importa salientar que a entrevista semiestruturada foi realizada na própria instituição com uma amostra (por acessibilidade) de 29 pessoas, sendo, oito profissionais da equipe multiprofissional de saúde (de um universo de dezesseis), dentre eles enfermeiro (responsável técnico), fisioterapeuta, nutricionista, psicólogo e técnicas de enfermagem, e 21 idosos assistidos (de um universo de $66)$. Salienta-se que, no decurso das entrevistas foi utilizada a observação com registro em diário de campo, com intuito de apreender aspectos subjacentes ao lócus da pesquisa não verbalizados pelos interlocutores.

Sinaliza-se que, pelo fato de as entrevistas terem sido realizadas em momentos distintos com os dois segmentos, foi possível oportunizar, nomeadamente aos entrevistados idosos, a liberdade de expressão, ou seja, não foi observado constrangimento de qualquer natureza na avaliação feita quanto ao trabalho dos profissionais.

Para facilitar a compreensão, os dados quantitativos foram dispostos em tabelas, recebendo, a posteriori, tratamento estatístico. Já os dados qualitativos foram tratados por meio da aproximação da análise de conteúdo de Bardin (2009). A análise de conteúdo consiste em desmontar a estrutura e os elementos do conteúdo a fim de esclarecer suas diferentes características e extrair sua significação, fazendo infe- rências ao seu conteúdo. Foram seguidas todas as etapas necessárias: pré-análise ou leitura flutuante, exploração do material ou codificação e tratamento dos resultados ou categorização. Ressalta-se que a alocação das categorias mais frequentemente identificadas nas falas dos interlocutores foram condensadas em eixos discursivos.

É importante destacar que este estudo foi cadastrado na Plataforma Brasil e enviado ao Comitê de Ética em Pesquisa da Universidade Estadual da Paraíba, sob o CAAE no ${ }^{\circ} 43234315.7 .0000 .5187$. O protocolo de pesquisa foi aprovado pelo Parecer no 996.433. Assim, foi realizado de acordo com os aspectos éticos, visto que os sujeitos concordaram em participar do estudo após a assinatura do termo de consentimento livre e esclarecido, conforme Resolução no 466/2012 do Conselho Nacional de Saúde, que institui as diretrizes e as normas regulamentadoras de pesquisas envolvendo seres humanos.

\section{Resultados e discussão}

\section{Perfil dos idosos assistidos}

Em relação aos dados demográficos da amostra de idosos, foram apresentados os seguintes resultados: maioria do sexo feminino $(57,0 \%)$, estado civil definido como solteiro (42,9\%), $38,1 \%$ dos entrevistados afirmaram nunca ter frequentado a escola ou não ter chegado a concluir a $1^{\mathrm{a}}$ série primária, a maioria declarou-se católica $(76,2 \%)$. Tem-se, desse modo, a constatação da feminização da velhice, já largamente sinalizada nos 
estudos de Salgado (2002) e de Camarano (2004), bem como do analfabetismo ou mesmo do analfabetismo funcional, apontado por Peres (2011).

No que se refere às profissões exercidas ao longo da vida, os dados mostram que a maioria dos idosos trabalhou como agricultor(a) $(19,1 \%)$ e como costureira $(14,3 \%)$. As outras profissões com maior representação na amostra foram comerciante, cozinheira, dona de casa e representante comercial com a porcentagem de 9,5\% em cada atividade. Assim, considerando o contexto brasileiro de precarização do trabalho no campo e nas áreas urbanas e o nível de informalidade provocado pelo capitalismo praticado no Brasil, infere-se que a amostra sinaliza um perfil de idoso empobrecido, cujas características já foram tratadas por Teixeira (2008). Tal perfil demanda da equipe multiprofissional, responsável pela produção do cuidado em saúde, um nível de compromisso maior em relação à visibilização dos direitos que lhes são garantidos legalmente.

Um dos eixos discursivos mais evidenciados pelos entrevistados institucionalizados refere-se à centralização da categoria médica, como se essa fosse a matriz da equipe multiprofissional. Também foi identificada a frequência com que os discursos auferem, às ações médicas, o poder de dar a dinâmica ao trabalho multiprofissional.

De acordo com os dados da Tabela 1, a maioria dos idosos conhece todos os profissionais de saúde que compõem a equipe multiprofissional $(47,6 \%)$.
No tocante às ações mais importantes desenvolvidas pela equipe, os dados revelam ser mais relevantes as atividades voltadas para a entrega de medicamentos e cuidados $(23,8 \%)$ como também a verificação de pressão arterial e a ida ao médico $(23,8 \%)$. Diante disso, percebe-se que os idosos assistidos associam como as ações importantes realizadas pelos profissionais de saúde aquelas vinculadas ao modelo curativo, ou seja, as atividades que priorizam a cura das doenças e dão ênfase ao atendimento médico, não atribuindo relevância a outras ações construídas pelo restante da equipe, tais como oficinas terapêuticas e rodas de conversa.

Em relação às ações de saúde que precisam melhorar na instituição, o maior número dos entrevistados $(42,9 \%)$ enfatizou a falta de médico diariamente na entidade para atendê-los. Quanto à esse aspecto, vale ressaltar que a Vila Vicentina Júlia Freire não mantém profissional de medicina contratado. Os médicos que atendem os usuários são voluntários e, geralmente, frequentam uma vez por semana o local. Já o atendimento médico que é disponibilizado pela Unidade de Saúde da Família é realizado por intermédio de visita quinzenal à entidade. 
Tabela 1 - Descrição da percepção dos idosos sobre as ações da equipe multiprofissional

\begin{tabular}{|c|c|c|c|}
\hline & & \\
\hline & & $\mathrm{F}$ & $\%$ \\
\hline \multirow{4}{*}{$\begin{array}{l}\text { Quais os profissionais da } \\
\text { equipe multiprofissional } \\
\text { que o idoso conhece? }\end{array}$} & Toda a equipe multiprofissional & 10 & 47,6 \\
\hline & Equipe de enfermagem (enfermeiro e técnicos) & 6 & 28,6 \\
\hline & NR & 3 & 14,3 \\
\hline & Médico; equipe de enfermagem e psicóloga & 2 & 9,5 \\
\hline \multirow{6}{*}{$\begin{array}{l}\text { Quais as ações da equipe } \\
\text { multiprofissional que foram } \\
\text { importantes para o idoso? }\end{array}$} & $\begin{array}{l}\text { Eles dão nossa medicação, ensinam o que não } \\
\text { sabemos e cuidam de todos nós }\end{array}$ & 5 & 23,8 \\
\hline & $\begin{array}{l}\text { Verificam a pressão, levam para o médico se } \\
\text { estiver com algum problema de saúde }\end{array}$ & 5 & 23,8 \\
\hline & $\begin{array}{l}\text { Conversam, visitam, atendem e cuidam muito } \\
\text { bem de nós }\end{array}$ & 4 & 19,0 \\
\hline & $\begin{array}{l}\text { Todas as atividades que eles fazem são } \\
\text { importantes }\end{array}$ & 3 & 14,3 \\
\hline & $\begin{array}{l}\text { Não soube especificar que atividade da equipe } \\
\text { multiprofissional foi importante }\end{array}$ & 2 & 9,5 \\
\hline & NR & 2 & 9,5 \\
\hline \multirow{5}{*}{$\begin{array}{l}\text { Na opinião do idoso, que } \\
\text { ações de saúde precisam } \\
\text { melhorar na instituição? }\end{array}$} & $\begin{array}{l}\text { Falta de médico diariamente para nos atender e } \\
\text { passar as medicações que precisamos }\end{array}$ & 9 & 42,9 \\
\hline & Não precisa melhorar nada, está tudo bem & 4 & 19,0 \\
\hline & $\begin{array}{l}\text { Não soube especificar o que precisa melhorar na } \\
\text { instituição }\end{array}$ & 3 & 14,3 \\
\hline & NR & 3 & 14,3 \\
\hline & $\begin{array}{l}\text { Consulta com o médico, exames, ter atividades } \\
\text { físicas e jogos para os idosos }\end{array}$ & 2 & 9,5 \\
\hline
\end{tabular}

Fonte: primária.

No que se refere a que categoria de profissional de saúde os idosos entrevistados sentem falta na instituição, grande parte $(42,9 \%)$ ressaltou que não sente falta. Contudo, um grupo $(28,6 \%)$ enfatizou que há necessidade da categoria médica para compor a equipe. Nesse ponto, percebe-se uma contradição, tendo em vista que a maioria dos idosos relatou não sentir a necessidade de algum profissional para compor a equipe, embora, anteriormente, $42,9 \%$ dos entrevistados tenham destacado que uma das ações a serem aperfeiçoadas na Ilpi seria a necessidade de atendimento médico diário.

No que diz respeito ao profissional de saúde informar acerca dos direitos que constam na legislação sobre a saúde dos idosos, a maioria dos entrevistados $(52,4 \%)$ afirmou que a equipe multiprofissional não divulga os direitos preconizados nos instrumentos legais. Em contrapartida, dos idosos que mencionaram que há essa divulgação, 19\% relataram 
que são os direitos estabelecidos pelo Estatuto do Idoso.

Ante o exposto, é relevante acrescentar que o Estatuto do Idoso em seu artigo 50 , inciso II, preconiza que dentre as obrigações das entidades de atendimento de longa permanência está a de "observar os direitos e as garantias de que são titu- lares os idosos". Para tanto, é importante que os representantes da entidade e os integrantes da equipe multiprofissional orientem e estimulem o conhecimento dos direitos determinados pela legislação bem como é essencial que repassem essas informações aos idosos e seus familiares.

Tabela 2 - Continuação da descrição da percepção dos idosos sobre as ações da equipe multiprofissional

\begin{tabular}{l|l|r|r} 
& & \multicolumn{1}{c}{ F } & \multicolumn{1}{c}{$\%$} \\
\cline { 2 - 4 } & Nenhum profissional & 9 & 42,9 \\
Que profissionais de saúde o idoso & Médico & 6 & 28,6 \\
sente falta na llpi? & Médico especialista e dentista & 3 & 14,3 \\
& Médico e fisioterapeuta & 2 & 9,5 \\
& Médico e farmacêutico & 1 & 4,8 \\
Os profissionais de saúde divulgam & Não & 11 & 52,4 \\
$\begin{array}{l}\text { para o idoso os direitos relacionados } \\
\text { à saúde que estão na legislação? }\end{array}$ & Sim & 10 & 47,6 \\
& Os profissionais não orientam sobre os & 11 & 52,4 \\
Quais os direitos já foram divulgados & direitos do idoso. & & \\
pela equipe multiprofissional para o & Estatuto do Idoso & Direito à saúde e alimentação & 19,0 \\
idoso na llpi? & O idoso não soube especificar sobre & 2 & 9,5 \\
& quais direitos os profissionais orientam & & 9,5 \\
\hline
\end{tabular}

Fonte: primária.

Ações da equipe multiprofissional da Vila Vicentina Júlia Freire

Em contraposição às percepções dos idosos acerca da equipe e de sua atuação no cotidiano institucional, constatou-se outra ordem discursiva nos conteúdos das falas dos profissionais: a justificativa (pela falta de capacitação continuada ou pelo perfil de formação profissional) de conhecer tangencialmente o escopo legal que protege o idoso nos aspectos que extrapolam o direito à saúde. Assim, quando foi perguntado aos profissionais se eles conheciam as diretrizes da PNSPI, 25\% afirmaram conhecê-las, citando o Estatuto do Idoso e a Caderneta de Saúde da Pessoa Idosa. Já 50\% dos profissionais disseram conhecê-las parcialmente, mencionando que o idoso tem prioridade nos serviços de atendimento de saúde, como na Estratégia 
Saúde da Família, além de se referirem ao Estatuto do Idoso, tendo em vista que tais profissionais pela natureza de suas atribuições (produzir o cuidado em saúde), dificilmente circulam por instituições e espaços socio-ocupacionais vinculadas a outras políticas sociais, tais como previdência social, habitação, dentre outras. No entanto, os outros $25 \%$ informaram que não conhecem ou nunca tiveram acesso às diretrizes da PNSPI, como é possível constatar nos depoimentos que se seguem: "Conheço o Estatuto do Idoso. Dentro da Estratégia de Saúde da Família, o idoso tem prioridade" (Entrevistado no 9) "Não conheço. Quem é da área social tem uma visão mais ampla destas questões" (Entrevistado n ${ }^{\mathrm{o}}$ 7).

De acordo com as respostas da equipe multiprofissional, nota-se que os profissionais não se referiram às diretrizes expressas na PNSPI, porém, fazem menção a outros instrumentos legais relacionados à garantia de direitos dos idosos.

Esse desconhecimento ou conhecimento superficial da legislação que rege a proteção social ao idoso poderia ser explicado pela inexistência de disciplinas que tratem dessa área temática com profundidade na maior parte dos cursos de graduação no Brasil, que relacionem a prática profissional à questão da velhice. Entretanto, não se pode justificar o desconhecimento da legislação já que está preconizado legalmente que:
O desenvolvimento e a capacitação de recursos humanos constituem diretriz que perpassará todas as demais diretrizes [...], de forma que o setor saúde possa dispor de pessoal em qualidade e quantidade adequadas, [...]. Merece especial atenção, sobretudo no tocante ao que define a Lei 8.080/90, em seu artigo 14 e parágrafo único, nos quais está estabelecido a formação e a educação continuada como mecanismo fundamental (GORDILHO et al., 2000, p. 38).

Outra questão proposta à equipe multiprofissional diz respeito às ações integradas com a rede pública de saúde na instituição. Todos os profissionais enfatizaram que tais ações acontecem, relacionando os seguintes serviços: campanhas de vacinação, medicamentos disponibilizados pelo Centro Especializado de Dispensação de Medicamentos Excepcional e pela Gerência de Medicamentos e Assistência Farmacêutica, o encaminhamento dos idosos para hospitais públicos quando necessário, o fornecimento de dietas pelo Núcleo de Atendimento à Dieta Especial, os atendimentos em parceria com a Unidade de Saúde da Família (USF).

É importante ressaltar que $25 \%$ dos profissionais destacaram que a rede pública de saúde deixa a desejar, principalmente em relação à presença de médicos na Ilpi, tendo em vista que o médico da USF realiza visita e atendimentos na entidade apenas quinzenalmente. É válido salientar a fala de um dos entrevistados: "Acho que a rede pública deixa muito a desejar, pois é quase como se não tivesse. A médica do PSF que só vem na instituição de quinze em quinze dias" (Entrevistado nํㅜ 5 ). 
No tocante à participação dos profissionais da equipe em capacitação ou especialização voltada para a saúde da pessoa idosa, 50,0\% dos profissionais afirmaram que participaram de palestras, simpósios e cursos voltados para as temáticas do idoso, dentre elas: Alzheimer e os cuidados com a pessoa idosa. Outros, 25,0\% dos entrevistados, realizaram capacitações relacionadas à sua área de atuação, como curso de atendimento pré-hospitalar e nutrição clínica, os demais $(25,0 \%)$ nunca participaram ou há mais de cinco anos não participam de qualquer capacitação. Isso explica, em parte, o "estranhamento" por vezes das equipes em relação ao aporte legal que protege o idoso brasileiro.

Diante do exposto, observa-se que conforme disposto na PNSPI, ainda há uma carência de qualificação para os profissionais atuarem na área do envelhecimento, em todos os níveis de atenção. Tal aspecto corrobora o estudo de Martins et al. (2007) no qual se constatou a incipiência de investimento no campo da formação de profissionais para atuação com a pessoa idosa. Nessa perspectiva, importa lembrar que a PNSPI propõe a capacitação de equipes multiprofissionais, visando à qualificação contínua do pessoal de saúde.

A qualificação profissional e a ampliação de pesquisas científicas na área gerontológica são imprescindíveis para se cuidar da pessoa idosa. Os profissionais de saúde que trabalham com idosos deverão perceber a necessidade de qualificação, para que oportunizem um cuidado específico e adequado (PIEXAK et al., 2012, p. 205).
Em relação aos desafios da equipe multiprofissional de saúde em sua atuação com idosos em instituições de longa permanência, foram citadas diversas questões: demora no atendimento nos serviços de saúde; ausência de abordagens sobre a importância de uma alimentação saudável para os idosos; insuficiência de recursos humanos; necessidade de capacitação para os funcionários; pouca interação e troca de experiências entre todos os profissionais; dificuldades financeiras e atuação de voluntários em vez de profissionais contratados. Com isso, torna-se fundamental citar a fala de um dos profissionais entrevistados:

A falta da presença de um médico constantemente na instituição, demora na marcação e realização de exames e consultas, falta de recursos humanos (cuidadores, técnicos e enfermeiro), a pouca participação dos familiares nas questões de saúde dos idosos institucionalizados, o excesso de atividades e cuidados, faltos de participação do poder público - instâncias municipal e estadual na liberação de profissionais de saúde; falta de profissionais na equipe multiprofissional (Entrevistado no 2).

Nesse sentido, fica explícito que a equipe multiprofissional identifica como uma das dificuldades encontradas no cotidiano de trabalho questões relacionadas, principalmente, aos recursos humanos, ou seja, a falta de profissionais, a necessidade de qualificação ou a troca de informações entre eles.

Além disso, indagou-se ao corpo técnico se ocorrem ações de prevenção de saúde com os idosos. Nessa direção, $62,5 \%$ dos profissionais ressaltaram que sim, relatando as seguintes ações: 
exames, consultas médicas, oferta de alimentação adequada, sessões de fisioterapia, momentos destinados a atividades físicas e lúdicas. Entretanto, 37,5\% da equipe afirmaram que tais ações não ocorrem, ou não tem conhecimento de nenhuma ação preventiva para os idosos residentes.

Foi perguntado aos integrantes da equipe se, na prática profissional, era oferecida orientação aos idosos residentes e/ou a seus familiares acerca dos direitos assegurados na legislação brasileira - Estatuto do Idoso, Política Nacional do Idoso, Política Nacional de Saúde da Pessoa Idosa. Dos profissionais entrevistados, $50,0 \%$ asseguraram que, às vezes, orientam os idosos e/ou familiares. Os outros $50,0 \%$ responderam que nunca orientaram.

Com base nesse resultado, pode-se reafirmar os dados apresentados na Tabela 2, visto que a maioria dos idosos $(52,4 \%)$ relatou que os profissionais não os orientam sobre os seus direitos. Dessa forma, evidencia-se a necessidade de a equipe multiprofissional conhecer os instrumentos legais que amparam os direitos dos idosos, além de orientá-los.

No que diz respeito ao fato de a Vila Vicentina Júlia Freire apoiar ou não o desenvolvimento de pesquisas e estudos na área do envelhecimento, $87,5 \%$ da equipe afirmaram que a entidade contribui e "abre as portas" para as pesquisas, em contraposição $12,5 \%$ afirmaram que não. Nessa perspectiva, torna-se relevante salientar as falas dos entrevistados:
À medida que estas pesquisas, estudos são realizados são produzidas informações e dados que no fim contribuem para o melhoramento da instituição enquanto órgão burocrático, como também pode melhorar a qualidade de vida do idoso e realizar o objetivo do pesquisador (Entrevistada $\mathrm{n}^{\circ} 3$ ).

[...] A partir do momento que a instituição abre as portas para as pesquisas, abre para novos conhecimentos. Ao mesmo tempo, a instituição e os pesquisadores crescem (Entrevistada $\mathrm{n}^{\mathrm{0}}$ 1).

Com base nos dados apresentados, percebe-se que os resultados indicaram que, diante das múltiplas necessidades dos idosos apresentadas à equipe multiprofissional, ainda faz-se necessário avançar na implantação das diretrizes propostas pela Política Nacional de Saúde da Pessoa Idosa, bem como de uma maior ampliação da atuação estatal na materialização de políticas sociais voltadas para a área do envelhecimento humano, as quais devem ter como diretiva a integralidade do cuidado.

\section{Conclusão}

O envelhecimento populacional é um fenômeno crescente, no entanto, conforme preconiza a PNSPI ainda faltam profissionais qualificados para atuarem em relação às necessidades e demandas multifacetadas desse público. De acordo com os resultados alcançados, percebe-se a feminização da velhice e o viés de empobrecimento dos idosos que vivem nas Ilpis filantrópicas no país. Constatou-se, ainda, que a equipe multiprofissional que atua na Vila Vicentina Júlia Freire procura desenvolver ações que estimu- 
lam o envelhecimento ativo e saudável, além de promover a atenção integral aos idosos, por meio de ações intersetoriais. No entanto, verificou-se a prevalência do modelo de atenção curativo. Nessa direção, a fragilidade de inserção da categoria médica na equipe se coloca como um problema, já que essa é nuclear na produção do cuidado em saúde. Ademais, constata-se a necessidade de formação continuada de toda equipe sobre a temática do envelhecimento, já que se evidenciou um conhecimento frágil sobre os aportes legais relativos à pessoa idosa no cenário brasileiro.

Ademais, não se pode descurar do fato de que a situação de atendimento ao idoso, de modo geral, não é refratária às características históricas do Estado brasileiro em relação à proteção social, profundamente marcada por inacessibilidade e restrição de gastos sociais. Além disso, vale ressaltar que, para além das questões estruturais que o sistema de proteção social brasileiro apresenta, vale lembrar que a preocupação com a saúde dos idosos é recente no país. No cenário do Sistema Único de Saúde, as ações ainda se ressentem de consolidação. No nível da atenção básica, as intervenções direcionadas aos idosos são pontuais e calcadas no modelo de campanhas, haja vista as realizadas em prol da imunização da população idosa. Os demais programas de saúde, tais como controle de diabetes e de hipertensão não são destinados exclusivamente aos idosos. A intervenção nesse nível de complexidade em saúde conta com pouquíssimas experiências municipais que se voltam à população idosa por meio de programas coletivos.

Em relação aos níveis de média e alta complexidade, a situação agrava-se, tendo em vista o contexto mais amplo de violação do direito à saúde para a população de modo geral. São nesses níveis de atendimento que as redes de atenção têm mais se ressentidos dos impactos do projeto privatizante na saúde.

Por fim, o estudo em pauta reafirmou a relevância da PNSPI já que, apesar dos reveses sinalizados, a proposta ainda se coloca como um instrumento norteador para melhor atender às demandas da população senil, pois visa a estimular $o$ atendimento das necessidades desse segmento de maneira integral, tendo em vista o crescente número de pessoas idosas que se coloca como um desafio para o Estado e a sociedade. Esse crescimento demanda a ampliação das políticas sociais direcionadas para as múltiplas necessidades da pessoa idosa como também o trabalho multiprofissional para a integralidade do cuidado.

\section{The contribution of the multidisciplinary teams for the visibility of the National Politics of Health of the Elderly}

\section{Abstract}

The population aging is a phenomenon that is occurring of fast and intense form in the Brazilian population. In this scene, laws had been established, would carry and decrees to mainly take care of the necessities of health of the aged population,

RBCEH, Passo Fundo, v. I3, n. 2, p. I43-156, maio/ago. 2016 
amongst these legal instruments - the National Politics of Health of the Elderly. The research had as objective to verify if the performance of the multidisciplinary team of health contributes for the knowledge and implementation of this politics next to the users attended for a long time institutions for the elderly located in João Pessoa/PB. It objectified to trace the profile of the aged ones attended and to catch the perception of these concerning the actions played for the multidisciplinary team and to investigate as it occurs to the boarding of the professionals and the model of attention to the health. Two instruments for the collection of these data had been used: the semistructuralized interview and the comment with register in daily of field. One was to a observacional study, field, of the descriptive type, quantitative and qualitative, carried through with a sample of 29 people selected for convenience, 08 specifically professional of the multidisciplinary team and 21 aged ones. The results has indicated the feminization of the oldness in locus of the research, what it corroborates with the start debate saw production of knowledge in this thematic field. Moreover, ahead evidenced that of the multiple necessities of the aged ones presented the multidisciplinary team, still is necessary to advance in the implantation and visibilization of social politics directed toward the completeness of the care, in view of that half of the consulted professional sample tangentially knows the apparatus legal that protects the aged one, what it excessively explains the lack of professional orientation in relation to the social rights certified by interviewed $52,4 \%$ of the aged ones.

Keywords: Elderly. Multidisciplinary team. National Health Policy for the Elderly.

\section{Referências}

AMAZONEIDA, P. Formação em serviço social, politica social e o fenômeno do envelhecimento. Comunicação apresentada em mesa-redonda no Seminário sobre Educação Superior e Envelhecimento Populacional no Brasil. Brasília, 12 maio 2005.

BARDIN, L. Análise de conteúdo. 4. ed. Lisboa: Edições 70, 2009.

BRASIL. Constituição da República Federativa do Brasil de 1988. Brasília: Senado Federal, 1988. Disponível em: <http://www. senado.gov.br/legislacao/const/con1988/ CON1988_06.06.2013/art_230_.shtm >. Acesso em: 5 nov. 2014.

. Ministério da Saúde. Portaria $\mathrm{n}^{\mathrm{o}}$ 2.528, de 19 de outubro de 2006. Aprova a Política Nacional de Saúde da Pessoa Idosa. Brasília, DF, 2006.

. Lei $\mathrm{n}^{\mathrm{o}} 8.842$, de 4 de janeiro de 1994. Política Nacional do Idoso. Brasília, DF, 1994.

. Presidência da República. Casa Civil. Subchefia para Assuntos Jurídicos. Lei ${ }^{\circ}$ 10.74 , de 1 de outubro de 2003. Dispõe sobre o Estatuto do Idoso e dá outras providências. Brasília, DF, 2003.

CAMARANO, A. A. (Org.). Os novos idosos brasileiros: muito além dos 60 ? Rio de Janeiro: IPEA, 2004.

CAMARANO, A. A.; EL GHAOURI, S. K. Idosos brasileiros: que dependência é essa? In: CAMARANO, A. A. (Org.). Os novos idosos brasileiros: muito além dos 60 ? Rio de Janeiro: IPEA, 1999. p. 281-306.

GORDILHO, A. et al. Desafios a serem enfrentados no terceiro milênio pelo setor saúde na atenção ao idoso. Rio de Janeiro: UnATI, 2000. (Envelhecimento Humano).

INSTITUTO BRASILEIRO DE GEOGRAFIA E ESTATÍSTICA. Estudos e pesquisas: primeiros resultados definitivos do Censo 2010. Comunicação Social. Brasília, 2011. 
Disponível em: <http://saladeimprensa.ibge. gov.br/noticias>. Acesso em: 20 jan. 2015.

MARTINS, J. J. et al. Políticas públicas de atenção à saúde do idoso: reflexão acerca da capacitação dos profissionais da saúde para o cuidado com o idoso. Revista Brasileira de Geriatria e Gerontologia, Rio de Janeiro, v. 10, n. 3, p. 371-382, ago. 2007.

MINAYO, M. C. S.; HARTZ, Z. M. A.; BUSS, P. M. Qualidade de vida e saúde: um debate necessário. Ciência \& Saúde Coletiva, Rio de Janeiro, v. 5, n. 1, p. 7-18, abr. 2000.

PAIVA, S. Envelhecimento, saúde e trabalho no tempo do capital. São Paulo: Cortez, 2014.

PERES, M. A. C. Velhice e analfabetismo, uma relação paradoxal: a exclusão educacional em contextos rurais da região Nordeste. Revista Sociedade e Estado, Brasília, v. 26, n. 3, p. 631-661, set./dez. 2011.

PIEXAK, D. R. et al. Percepção de profissionais de saúde em relação ao cuidado a pessoas idosas institucionalizadas. Revista Brasileira de Geriatria e Gerontologia, Rio de Janeiro, v. 15, n. 2, p. 201-208, abr. 2012.

SALGADO, C. D. S. Mulher idosa: a feminização da velhice. Estudos Interdisciplinares sobre o Envelhecimento, Porto Alegre, v. 4, p. 7-19, 2002. Disponível em: <http://seer. ufrgs.br/index.php/RevEnvelhecer/article/ view/4716/2642. Acesso em: 2 mar. 2016.

SILVA, P. A. et al. Atuação em equipes multiprofissionais de saúde: uma revisão sistemática. ConScientiae Saúde, São Paulo, v. 12 , n. 1, p. 153-160, 2013.

SPOSATI, A. Modelo brasileiro de proteção social não contributiva: concepções fundantes. In: UNESCO/MDS. Concepção e gestão da proteção social não contributiva no Brasil. Brasília, 2009. Disponível em: <http://unesdoc. unesco.org/images/0018/001830/183075por. pdf>. Acesso em: 2 mar. 2016.

TEIXEIRA, S. M. Envelhecimento e trabalho no tempo de capital: implicações para a proteção social no Brasil. São Paulo: Cortez, 2008.
VERAS, R. Envelhecimento populacional contemporâneo: demandas, desafios e inovações. Revista Saúde Pública, São Paulo, v. 43, n. 3, p. 48-54, maio/jun. 2009. Disponível em: $<$ http://www.scielo.br/pdf/rsp/v43n3/en_224. pdf>. Acesso em: 5 nov. 2014. 